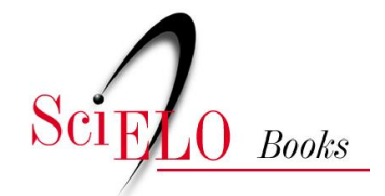

\title{
São Cristóvão
}

a redenção pelo amor fraternal na escrita da maturidade em Eça de Queiroz

\author{
Aldinina Medeiros
}

\section{SciELO Books / SciELO Livros / SciELO Libros}

MEDEIROS, A., org. São Cristóvão: a redenção pelo amor fraternal na escrita da maduridade em Eça de Queiroz. In: Travessias pela literatura portuguesa: estudos críticos de Saramago a Vieira [online]. Campina Grande: EDUEPB, 2013, pp. 127-145. ISBN 9788578792794. Available from SciELO Books $<\underline{\text { http://books.scielo.org }>}$

\section{@)(1)(9)}

All the contents of this work, except where otherwise noted, is licensed under a Creative Commons Attribution-Non Commercial-ShareAlike 3.0 Unported.

Todo o conteúdo deste trabalho, exceto quando houver ressalva, é publicado sob a licença Creative Commons Atribuição Uso Não Comercial - Partilha nos Mesmos Termos 3.0 Não adaptada.

Todo el contenido de esta obra, excepto donde se indique lo contrario, está bajo licencia de la licencia Creative Commons Reconocimento-NoComercial-CompartirIgual 3.0 Unported. 


\title{
São Cristóvão: \\ a redenção pelo amor fraternal na escrita da maturidade em Eça de Queiroz
}

\author{
Aldinida Medeiros
}

Em nenhuma outra criação seu espírito se move com tamanha liberdade. Na livre e alada inspiração, na riqueza e profundidade do símbolo, na comunhão directa e enternecida com a natureza, o "S. Cristóvão" afigura-se-nos um dos mais belos poemas jamais escritos em língua portuguesa.

\section{Jaime Cortesão}

De novo Cristóvão correu o mundo, servindo aos homens. Pelos descampados e pelos povoados, por longos Invernos, [...], corre o mundo, oferecendo seus braços. Os anos tinham passado, e Cristóvão era mais velho que os mais velhos carvalhos. [...] Mas cada dia o seu coração se enchia duma ternura maior e mais vaga. Por vezes, sentado numa pedra, à beira dum caminho, olhava as árvores, os campos [...] e sentia então como o desejo de apertar 
toda a terra contra seu peito. Depois pensava que sobre ela viviam tantos miseráveis, tantos humildes, tantos enfermos, - e era um desejo de sondar até aos últimos recantos aquele mundo e de curar cada dor, matar cada fome, tornar o mundo alegre, são, perfeito.

Eça de Queiroz

Apresentando um enredo que se diferencia do estilo característico de seus romances realistas, essa narrativa adquire uma tônica singular e proporciona ao leitor uma dinâmica de leitura bem diferente de suas demais obras, sobremaneira as mais conhecidas da crítica e do público. Publicado no volume póstumo Últimas páginas, São Cristóvão é uma versão da vida do to católico, narrada de uma forma magistral por Eça de Queiroz ${ }^{1}$ e integra as Lendas de santos ${ }^{2}$, juntamente com duas outras: São frei Gil e Santo Onofre.

Nesse breve estudo, observaremos alguns importantes aspectos dessa novela. Primeiramente, porque Eça se afasta, em muito, da escrita naturalista desenvolvida nos romances do início de sua carreira literária. Em segundo lugar, convém destacar o autor busca nos temas religiosos

1 Por opção convicta utilizo em todo o meu texto a grafia portuguesa do nome do escritor tal qual sua época de registro de nascimento: Queiroz, embora reconheça que os acordos ortográficos modificaram esta grafia atualmente para Queirós. Todavia, nas referências, respeito a grafia utilizada pelos críticos em seus ensaios e mantenho aquela que por cada ensaísta foi adotada. Com os adjetivos, o uso é normal: queirosiano, queirosiana.

2 Últimas Páginas foi um volume organizado por Luís de Magalhães e editado pela Editora Lello e Irmão, em 1912. Em 1966, Maria de Queiroz, filha de Eça, prepara uma nova edição e mantém o nome Lendas de Santos, dado já na publicação anterior. 
uma demonstração de crença que difere daquela doutrinária "imposta" pela religião católica e constrói um santo universalista, símbolo da caridade, mas desloca-o de sua origem e tempo, o que é bastante peculiar, conforme a assertiva de Cortesão:

[...] ao transportar o Santo da Antiguidade para os últimos séculos medievais e do Próximo Oriente para o Ocidente, o escritor deu apenas o primeiro passo para universalizar a sua criação. Da lenda primitiva, tal como apareceu na Légende Dorée, de Jacques de Voragine, o romancista aproveita apenas o final [...] (CORTESÃO, 2001, p. 123).

Poderia, pois, ser tal recurso literário para uma identificação do leitor com o santo. Cristóvão ali, tão perto, nascido de servos, e tendo vivenciado os grandes acontecimentos da Idade Média; um Cristóvão europeu, talvez mais perto dos portugueses que da Ásia, pois que asiático ele já era em sua verdadeira nacionalidade. Cabia, então, à ficção trazer a lenda para mais próximo e assim irradiar Cristóvão para outras nações e, por que não (?) continentes.

Outrossim, porque, para escrever o São Cristóvão, Eça de Queiroz baseia-se na vida de alguns santos, como, por exemplo, São Francisco de Assis. Para expor sua visão, com base nas leituras proudhonianas, do cristianismo social, ou seja, do cristianismo que vai, tal como na vida de Cristóvão, o protagonista, da fé à caridade da ação com base nos ensinamentos do Cristo. 
O enredo dessa novela é sobre a vida do filho de um lenhador e de uma fiandeira, servos humildes e bons de um feudo qualquer. A chegada desse filho - Cristóvão - é anunciada ao pai por um anjo, o que remete a narrativa à intertextualidade explícita com a anunciação que Maria, mãe de Jesus, recebeu do anjo Gabriel, um dos muitos vínculos ficcionais do texto com a lenda contada pela versão do cristianismo. A criança, portanto, passa a ser muito esperada, mas, ao nascer, decepciona os pais pela feiura. Nasce enorme, com uma estrutura corpórea avantajada e em tudo diferente do que sonharam, principalmente por se tratar de um filho anunciado por um anjo, que, na ansiedade dos pais, deveria ser de feições como a do Cristo. Ao contrário disso, nasce:

Escuro, coberto duma pele rugosa e áspera: com uma face vaga, informe, onde as feições faziam como vagas protuberâncias nodosas; as mãos enormes enclavinhadas sobre o ventre felpudo; torto das penas que findavam em dois pés agudos, como os dum fauno, - todo ele parecia uma raiz sombria, raiz de árvore estranha, ainda negra da terra negra de que fora arrancada. E nem gemia. Era como um rudimento dum ser vegetal (QUEIROZ, 2002, p. 22)

Os pais, apesar de ampará-lo e criá-lo no convívio normal da família, não eram apegados ao menino, viam em sua feiura física a concretização da decepção pela qual passaram, pois Cristóvão havia sido anunciado por um anjo. Em visível intertextualidade bíblica, seu nascimento teve uma 
aura de prenúncio, como o do Menino Jesus. Mas ao contrário, Cristóvão nasce feio; seus pais sofrem pelos comentários da vizinhança, todos temem o menino que cresce avantajadamente. A enorme diferença de Cristóvão chega mesmo a deprimir sua mãe e esta sucumbe ao desgosto de ter um filho com aparência tão monstruosa. E, para piorar toda a situação, até os quatro anos, o menino não falava, não emitia uma palavra.

O único som que saía cavo e grosso, dos seus lábios cor de autora, era Hã! Hã! Se tinha sede apontava com um grande dedo, rosnava: Hã! Hã! [...] A pobre mulher já perdera a doce esperança de o ouvir jamais chamar mãe e pai. Já não duvidava de ter concebido um imbecil, um mudo. [...] Já na aldeia, entre os servos do castelo, corria que o filho do lenhador era um monstro. (QUEIROZ, 2002, p. 25).

É neste ser tão rudimentar e tão diferente das formas humanas, comumente aclamadas pela beleza, que os ensinamentos sobre o amor ao próximo serão, magistralmente, expressados por Eça de Queiroz. Justamente por ter sido rejeitado, desde cedo, e todos terem se afastado em decorrência de seu aspecto monstruoso, o menino cresce solitário, tendo como companhia constante apenas os seres da natureza: os pássaros, a vegetação. Todos esses o reverenciam de uma forma harmônica, em contraponto aos maus tratos que vão lhe desferir, em todo o texto, os seres humanos. Por isso, talvez, ele esteja configurado como uma imagem de constante oposição entre a força da natureza - sobretudo o instinto humano - e a civilização, entre 
o paganismo e o cristianismo, pois, embora voltado para a prática da caridade, Cristóvão desconhece, durante quase toda a narrativa, a doutrina católica.

Outro aspecto que observamos são algumas referências ao paganismo, em sutis correlações entre o protagonista e o deus da mitologia, Pã, tal como se pode observar na caracterização "pés de fauno" de Cristóvão. De modo que o protagonista é um ser híbrido, notadamente com características de Cristo e de Pã e revestido do amor pela natureza que caracteriza o franciscanismo, pois, a seguirmos as palavras de Jaime Cortesão, "[...] desde a correspondência de Fradique Mendes se multiplicam na sua obra as referências a S. Francisco de Assis" (CORTESÃO, 2001, p. 78). O que se pode, aliás, constatar no Frei Genebro, que, segundo a descrição, no conto de mesmo nome, era amigo e discípulo do fundador da ordem fransciscana.

Na novela aqui em estudo, através do hibridismo presente em Cristóvão, Eça de Queiroz constrói um ideário panteísta, através de irrupções pulsionais do instinto, dando voz à natureza. Em diversos trechos, o próprio Cristóvão é parte da natureza, confundindo-se com esta ou mesmo irrompendo daí como um ser vegetal. Mais que isso, Cristóvão ama a natureza, ela é seu abrigo, sua casa e, por vezes, parece ser sua própria alma:

[...] Já corria a sua grossa mão sobre a doçura dos musgos; trepava aos troncos para espreitar para dentro da densidão das folhagens; estirava-se no meio das relvas altas, rolando os seus cabelos crespos pela brancura das margaridas. $\mathrm{E}$ ao mesmo tempo descobria, dentro 
de toda esta natureza, uma vida múltipla, vasta, ativa e maravilhosa. A terra, que ele remexia com seus dedos grossos, estava toda mole dos vermes que a habitavam; cada hastezinha de relva abrigava um povo de insetos, mais numerosa que a gente da aldeia [...] (QUEIROZ, 2002, p. 33).

Triste, perdido e solitário é condição de Cristóvão, após a morte do pai, com quem vivera harmonicamente desde que a mãe morrera. É, como sempre, na natureza que ele se refugia até se refazer da dor pela perda dos dois entes queridos. "Quase esquecera os homens: e no seu espírito simples apenas muito confusamente restava a memória dos casais, dos lugares, e das crianças rindo [...]" (QUEIROZ, 2002, p.38). Sua jornada de peregrinações (de/por) amor ao próximo se inicia após muito tempo isolado na montanha refazendo-se dessas perdas. Nesse ínterim, Cristóvão é já adulto, e a população da aldeia se espanta diante de sua figura e da descomunal altura:

O seu vasto corpo crescera ainda, e a sua grenha ruiva ia mais alta que as mais altas árvores; lento nos movimentos, cada um dos seus passos parecia despregar-se do chão, com dificuldade; todo ele cheirava a torrão e a arvoredo; uma barba ruiva, como um capim queimado, cobria-lhe a face: - e os seus olhos azuis conservavam, como os duma criança, um espanto perpétuo. (QUEIROZ, 2002, p. 39). 
O amor ao próximo como temática não se resume unicamente a esta novela. Em diversos contos, como Frei Genebro, A morte de Jesus, O Suave Milagre, Eça se dirige ao tema do cristianismo. Não no sentido de explicar ou combater a religião católica. Mas, como se estivesse a dar um testemunho de que acredita nas ações de um evangelho pragmático, que deveria ter sido sempre muito mais vivenciado pelo clero que servido de doutrinação à população em massa.

Sabemos que, em vários textos, Eça explora esse lado místico da vida, embora grande parte dos leitores conheça apenas o Eça realista-naturalista, aquele da intensa crítica aos padres, ao molde de um Amaro e do Cônego Dias, ou às beatas, como a Senhora Joaneira e a Titi em A relíquia. A crítica através destas personagens é clara: viviam preocupados em pregar - uma doutrina que não praticavam - e levar uma vida muito cômoda. Crítica esta que, aliás, está muito bem fundamentada ideologicamente no discurso de uma das suas personagens mais elaboradas, como se vê nitidamente em $\mathrm{O}$ crime do padre Amaro. $\mathrm{O}$ sacerdote que seduz Amélia é o ápice desse comodismo dado ao clero da época.

Contudo, há, ao que nos parece, uma admiração velada do escritor pelos santos que escolhiam a vida no deserto, a vida rigorosa e simples, que mais imitavam a Jesus. Exemplo disso é a santidade que ele atribuiu ao cardeal Manning, realizando certa comparação deste com São Francisco de Assis.

Em parte, isso não é puramente original nesse escritor, pois se deve também ao ideal da geração de 70 , visto 
que semelhante postura também se percebe em Guerra Junqueiro - A velhice do padre eterno - e em alguns poemas de Antero de Quental. A própria figura de João Eduardo, em O crime do padre Amaro, já esboça - e aqui dizemos com ênfase que apenas esboça - esse pensamento queirosiano, de que não é preciso ser submisso à religião para ser bom, para ser honesto e ter valores humanitários. Assim, apesar de sabermos que as lendas referentes aos três santos estão situadas no contexto da fase da maturidade literária do autor de Frei Genebro, lembramos que essa linha temática se faz presente em sua obra, ainda que em esboço, desde muito tempo. Fácil de constatar esta observação é exemplificarmos que a mesma ideologia que aponta um messianismo, um encaminhamento profético no Suave milagre, encontra-se também no São Cristóvão.

Beatriz Berrini, em seu ensaio Sobre santos e santidade em Eça de Queirós assegura que:

Eça de Queiroz na maturidade, por exemplo, deu um testemunho sério e comovente a respeito daquilo que entendia por santidade, ao escrever sobre o cardeal Manning, por ocasião do seu falecimento [...]. (BERRINI, 2004, p.13).

Em vários textos seus, há menções a Deus, à natureza, a um modo de viver cristão que denotam um olhar bem peculiar, uma crítica tipicamente eciana ao desvio de uma santidade praticada outrora pelos religiosos, sobremaneira 


\section{6}

aos moldes franciscanos. De acordo com Berrini, aludindo à adesão de Eça às novas doutrinas do final do século XIX:

Tal atração poderia justificar-se pela sua profunda frustração ante a disparidade existente entre a doutrina evangélica e sua prática pelos cristãos, sobretudo os mais categorizados. Ou não? Não terá, ele também, bebido o pessimismo schopenhaueriano, tão disseminado entre os intelectuais, e a tal ponto que o fará repetidamente presente n'A cidade e as serras? Não terá havido uma influência da França, que então passava por uma renovação espiritual, como ele próprio recorda no seu Positivismo e Idealismo? (BERRINI, 2004, p. 17).

Faz-se importante destacar que dois aspectos norteiam a escrita das Lendas de Santos: uma visão que Eça de Queiroz tem do socialismo cristão, ou seja, o Cristianismo como opção pragmática mais que doutrinária, e uma adesão ao franciscanismo como um dos exemplos da prática do amor e caridade ao próximo. $\mathrm{O}$ autor de $O$ primo Basílio já esboçara desde cedo sua visão mística da vida, num sentido de compreensão que em muito divergia do tipo de prática religiosa que se cultivava no século XIX. Ainda muito jovem, no jornal Districto de Évora, pela verve cronista, ele escreve:

Nós às vezes esquecemos d'Ele, de Deus. Andamos tão atentos ao nosso pequeno palmo de terra, tão atarefados às nossas agitações imperceptíveis, que não vemos quem lá em cima, entre a luz serena e a pureza imarcescível, fecunda e retrai a vida. (QUEIROZ, 2000, p. 411). 
Corrobora com as palavras do próprio escritor o ensaio de Jaime Cortesão, Eça de Que e a questão social, no qual encontramos que:

De 1892 até 1898 em que podemos acompanhar, ano a ano na Gazeta e na Revista Moderna, as suas reacções íntimas perante os acontecimentos internacionais, vemos aquela tendência para uma espécie de socialismo espiritualista [...] progredir e definir-se.

Para ele, socialismo e santidade passam a fundir-se nas suas mais altas expressões; e os grandes progressos do movimento socialista realizam-se no íntimo das consciências, que acordam para a fraternidade universal. (CORTESÃO, 2001, p. 58).

Ambientada na Idade Média, a narrativa do São Cristóvão nos permite um "passeio" por vários momentos e alguns dos principais acontecimentos que marcaram esse período de intenso domínio da Igreja, que chega praticamente à tirania com o Tribunal do Santo Ofício. A grande mortandade e o estado desolador em que ficou a Europa com a Peste Negra - numa cena comovente em que são enterrados os cadáveres abandonados -, o culto ao demônio, pelas invocações de magia negra, tendo as bruxas como figuras satânicas, ou o momento em que os camponeses se revoltam contra os nobres - a Jacquerie - são destaques do enredo. Entretanto, nenhuma dessas alusões é feita de forma explicitamente nomeada. Tudo está ali, possível de ser percebido no texto, diluído, fluido, a mercê da percepção do leitor. O Eça que escreve o São Cristóvão, escritor já maduro e com larga experiência acumulada, trabalha bem 
o jogo da percepção, possibilitando pistas envolventes para que o leitor adentre a tessitura densa e, por vezes, um tanto lúdica, do seu jogo narrativo.

Podemos destacar dois desses momentos como marcantes para exemplificar a trajetória de Cristóvão: primeiro, a exaltação do amor servil, quando, em contato com a peste negra que assolara toda uma aldeia, ele socorre os doentes, dá-lhes água, limpa as ruas, enterra os mortos, enfim, cuida dos que ali ficaram esquecidos pelos que fugiam da contaminação fétida dos ferimentos causados pela doença. Cristóvão ignora tudo isso em nome do seu amor extremado pelo próximo:

Então o homem aconselhou que fugisse, porque a cidade toda morria de peste negra. [...] Atrás, outros homens, de faces sinistras, com correntes aos pés, traziam outros mortos... Eram os forçados das galés, que iam enterrar os mortos [...] Cristóvão tomou aos ombros os dois mortos que jaziam junto à fonte e começou a seguir os forçados. [...] Cristóvão sacudiu as mãos da terra, e sem atender aos brados dos soldados que o chamavam recolheu a cidade [...] Então, durante todo o dia percorreu as ruas, socorrendo os que caíam, desviando os mortos das calçadas - e ao escurecer já se tornara tão familiar, que das gelosias gritavam: 'Eh homem!' Ele vinha, carregava os mortos para a vala, limpava a imundície dos pátios, corria a encher as bilhas de água e mesmo alimentava as crianças que choravam sozinhas nos seus casebres. (QUEIROZ, 2002, p. 58).

O outro momento é quando Cristóvão lidera os Jacques, pondo-se a serviço destes na luta por comida e justiça social. 
Esse é o principal momento em que, na novela, Eça instaura sua visão resultante das leituras socialistas, pondo o santo católico em meio aos trabalhadores explorados e suas lutas sociais, diferenciando-o da visão somente milagreira que é comum ser atribuída aos santos católicos:

Mas então, dentre a multidão que embaixo se agitava, um velho avançou, sem armas, com um ramo de oliveira na mão, - e caminhou para Cristóvão. Ao meio da colina parou, e erguendo os braços perguntou a Cristóvão porque os atacava ele, servo, que decerto sofria da servidão, a eles, servos também, que no fim de tantos tempos de sofrimento só queriam partilhar de algumas das doçuras da terra? (QUEIROZ, 2002, p. 100).

Cristóvão, que primeiramente reagira ao grupo de revoltosos, ao conhecer seus motivos, passa a segui-los e defendê-los, sendo-lhe atribuída pelo narrador a imagem de um pai que cuida dos filhos; momento único em que assume uma espécie de comando de uma situação:

Então começou, de castelo em castelo, através das províncias a marcha dos Jacques. Das aldeias por onde eles passavam corriam a juntar-se-lhes miseráveis, servos revoltados, mendigos. Agora era uma multidão imensa que enchia os caminhos. Mas não havia neles nem violência, nem cólera. Iam mostrando, através das baronias ricas, a sua miséria de servos, e sem violência pediam esmola. Cristóvão era como um grande pai, que mendigava com os seus filhos, pelos caminhos [...]. (QUEIROZ, 2002, p. 105). 
Vejamos que a ideia do "grande pai", mendigando com seus filhos pelos caminhos, atribui analogamente a Cristóvão uma das categorias da Trindade, em que há o pai, o filho e o espírito. Aspecto este que só se torna pertinente ao leitor que consegue adentrar a tais dicas que anteriormente mencionamos. Nesse caso, a imagem de Pai, relacionada a um movimento de intensa barbárie, como é caracterizada a Jaccquerie, faz-nos deduzir que tem a função de abrandar o próprio caráter sanguinário do movimento. A imagem doce e sincera do gigante Cristóvão, a guiar aqueles camponeses famintos de justiça, remete a uma justiça messiânica. Aponta para uma solução encontrada por uma revolução através do amor muito mais que através do massacre.

Diante de uma novela cuja narrativa seduz não só pela linguagem, mas também pela articulação temática, compondo uma época da qual se extrai fatos marcantes, com um narrador astuto que leva o leitor à reflexão, muitas observações surgem, e a novela queirosiana São Cristóvão pode-se tornar um manancial para estudos diversos. Eça, já em fase final de sua escritura, com bastante experiência literária, elabora um santo que é um puro exemplo de amor à natureza, um panteísta, um ser cristão que, entre outras coisas, personifica o deus pagão Pã. Esse Cristóvão, um gigante com força hercúlea, heterodoxo, é a própria metáfora do instinto, da força, e do amor à natureza, lugar onde sempre se refugia quando maltratado pelos seus semelhantes.

É de se perguntar, pois, o que levaria um escritor como Eça de Queiroz a escrever três lendas de santos - duas delas 
não concluídas, São Frei Gil e Santo Onofre - e um dicionário de milagres, se tanta crítica há, em seus romances, ao clero e à Igreja Católica. Todavia, é justamente o feitio que nosso autor vai dar aos santos que diferenciará seu estilo nessa escrita hagiográfica. Partindo disso, é algo curioso as lendas de santos não terem como personagens os santos de destaque da Igreja: São Pedro, São Paulo, São Francisco, ou o próprio Santo Antônio, que é de origem lisboeta. Todavia, uma possível explicação é que o Flos Sanctorum, muito consultado por Eça de Queiroz, apresenta uma lenda do São Cristóvão que pode ter sido a base de sua novela.

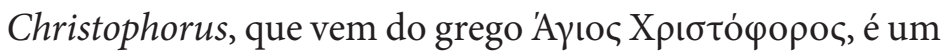
santo sobre o qual pouco se sabe. A lenda divulgada pela Igreja Católica ganhou dimensões muito maiores que acabaram por ocultar a biografia.

Por esse caminho, podemos inferir que a visão eciana dos santos - sobremaneira os escolhidos para as lendas e também São Francisco - seriam uma espécie de resposta do escritor às próprias críticas por ele levantadas ao longo de sua obra. O momento da escrita das Lendas de santos é um período em que se revive o neo-franciscanismo na Europa. E São Francisco era, por essência, um panteísta. Não é de se admirar, pois, que em várias passagens de seus textos, Eça aborde a natureza como um elo que leva a Deus. Esse seu modo panteísta de enxergá-la é, possivelmente, o que o faz mencionar aspectos da vida em retiro, no texto Santo Onofre.

O texto que resulta dessa escritura rica e amadurecida bem poderia ser intitulado "Uma fábula sobre a estupidez humana”, afinal, nessa leitura de Cristóvão enquanto santo 


\section{2}

da Igreja católica, Eça faz com que nos deparemos o tempo inteiro com demonstrações de egoísmo, insensibilidade e perversidade humanas:

Se o injuriavam, baixava a face humildemente. Se o espancavam ficava imóvel e quieto sob os golpes. Se o despediam, apanhava o seu bordão e partia suspirando. [...] Se havia algum grande lamaçal, ficava à beira dele para passar aos ombros os homens e os animais. Era ele que partia as rochas, para se construírem caminhos. E nas florestas onde sabia que deviam passar caravanas de mercadores, acendia grandes fogueiras para afugentar javalis. (QUEIROZ, 2002, p. 111).

Tudo isso vivencia o protagonista, que suporta, sem entender, a maldade alheia, não obstante a sua vontade premente de ajudar a todos que conhece ou quem cruza seu caminho; e há, ainda, sua ingenuidade e bondade constantes para com todos os seus semelhantes.

Chamamos a atenção para a escrita das Lendas de santos, especialmente o São Cristóvão, a fim de também mostrarmos essa nuança da escrita queirosiana: Eça como um historiador crítico dos temas relacionados à santidade. Apesar de escrever num tom menos ácido, aliás, em tom bem mais ameno em relação aos textos de cunho essencialmente realista/ naturalista, nos quais predominava a crítica social, Eça deixa entrever sua posição em relação à igreja, à classe abastada da sociedade, ou seja, os valores que estiveram fortemente presentes em seus textos nomeadamente realistas ainda ecoam em São Cristóvão, mas agora de forma diferente. 
Uma das maneiras de pensar a santidade está na versão prática de vivenciar o evangelho e, justamente por isso, os acontecimentos no enredo de São Cristóvão vão da caridade para a militância. Cristóvão, longe de ser somente o santo configurado pelo misticismo medieval, vai do serviço aos pobres à revolução em favor destes. Torna-se, portanto, um agente de revolução social. Eça, que assistira à fermentação das novas ideologias advindas da ideia de revolução e tinha em sua preferência de leitura os livros de Proudhon, constrói seu Cristo-Pã - Cristóvão - mais voltado para as teorias socialistas.

O próprio Eça faz referência a essa sua visão socialista de mundo - que para ele seria melhor religião que o cristianismo - em Cartas de Inglaterra, quando afirma:

[...] talvez um dia, quando o socialismo for religião de Estado, se vejam em nichos de templo, com uma lamparina de frente, as imagens dos santos padres da revolução: Proudhon de óculos, Bakunine parecendo um urso sob as suas peles russas, Karl Marx apoiado ao cajado simbólico do pastor de almas tristes. (QUEIROZ, 2006).

É com base em tais palavras que nos sentimos motivados a buscar, em textos aparentemente hagiográficos, um socialismo pragmático, queirosiano, pois um olhar mais atento aponta-nos que a narrativa do São Cristóvão é, ao mesmo tempo, até mais que a história de uma época, conforme mencionamos acima. É a história de uma consciência. Dentro da perspectiva da ideologia da geração de 70, o 
século XIX não só pretendia reformular instituições, como pretendia reconstituir uma nova visão da História, acrescentando-lhe uma visão crítica, voltando o enfoque para uma visão de igreja mais inocente, mais pura, menos doutrinária, com um Deus menos severo e padres exercendo menos poderes sobre as almas humanas; o que possibilitaria uma visão do homem e do mundo dentro de um idealismo renovador.

Um autor com uma prosa de densidade poética como a que se constata na obra de Eça, um escritor que, diplomata, preocupou-se com questões políticas e humanitárias como o caso dos Coolies, em Cuba - demonstrando o olhar do ser humano preocupado com seus semelhantes. Esse é o Eça de Queiroz que encontramos no São Cristóvão.

\section{Referências}

AGUIAR, Cláudio. Eça de Queiroz e a crise do nacionalismo. Estudos Portugueses: 150 anos de Eça de Queirós. Estudos Portugueses, Recife: Associação de Estudos Portugueses Jordão Emerenciano, n. 6, p. 63 - 72, 1996.

BERRINI, Beatriz. Sobre santos e santidade em Eça de Queiroz. Estudos Portugueses, Recife: Associação de Estudos Portugueses Jordão Emerenciano, n. 7, p. 13-23, 2004.

CORTESÃO, Jaime. Eça de Queiroz e a questão social. Lisboa: Imprensa nacional Casa da Moeda, 2001. 
QUEIROZ, Eça de. Cartas de Inglaterra. Disponível em < http://purl.pt/93/1/iconografia/imagens/ je76v_18860220_189/je76v_18860220_189.html > Acesso em: 20 set. 2006.

. Dicionário de milagres. v. 26. Lisboa: Livros do Brasil, [s/d]. V. 26.

- Vidas de Santos: São Cristóvão, Santo Onofre e São Frei Gil. São Paulo: Casa da palavra, 2002.

. Obras Completas. Rio de Janeiro: Nova Aguilar, 2000. V. 3.

RODRÍGUEZ, Joel. O estudo de Guerra da Cal sobre A Relíquia e a luta por um novo discurso canonizador queirosiano. Queirosiana: estudos sobre Eça de Queiroz e sua geração. Fundação Eça de Queiroz, Portugal, 2002/2003. p. $53-72$.

REIS, Carlos.; LOPES, Ana Cristina M. Dicionário de teoria literária. Petrópolis: Vozes, 1988.

REIS, Carlos. Eça de Queirós e a literatura como ficção. In. ENCONTRO INTERNACIONAL DE QUEIROSIANOS: 150 anos com Eça de Queirós, 3, 1997, São Paulo. Anais... São Paulo: Centro de estudos portugueses/FFLCH/USP, 1997. p. 17 - 28. 